back on the system, may be attributed the torpor, which is so well-known a symptom in suppression of urine. If this idea be correct it would lead to this practical precaution-viz., to be careful even in cases of cholera how we entirely suppress the alvine discharges till the urinary secretion be re-established, should there be any disposition to torpor. Certainly in the case I have mentioned as having been lately under my care, the mental torpor came on after the purging had ceased and before the urinary secretion was properly established, and it was not the effect of opium.

It will be evident, from the preceding remarks, that I am not prepared to assent to Mr. Salter's opinion on the nature of the difference between Asiatic and English cholera, but that I look on them as identical in fundamental character, though, from circumstances which I believe we do not understand, differing very widely in intensity; and, from what I saw of Asiatic cholera, I do not believe it to be any more contagious than English cholera-i. e., not at all. Certainly, in some of the neighbourhoods it attacked, there were local circumstances which might have given any disease a character of intensity; thus one of the spots which most suffered from its ravages at the West-end was a line of buildings at the back of Grosvenor-place, and I remember its being stated that the drainage in that neighbourhood was particularly bad.

Who would imagine at first sight that the innocent cow-pox was but a modification of the virulent smallpox? In this case experimental investigations have proved what are the modifying circumstances, and it requires, I think, no high degree of credulity to believe that such differences as exist between Asiatic and English cholera might arise from circumstances, the nature of which it may be granted we are at present ignorant of. The proverb of Solomon that "there is nothing new under the sun" is not inapplicable to pathology, nor will it be till the human constitution and the circumstances under which it is placed become changed.

Much as I respect an experience of thirty years, I cannot agree with Mr. Salter, that " the English cholera, though occasionally a fatal complaint, is rarely attended with much danger." Certainly it has been my lot to be called, and not unfrequently, to cases where I verily believe that another hour's unchecked duration of the symptoms would have reduced the patients to a state insensible to the influence of medicine. I do not say that there is much field for the exhibition of skill, but there is for decision and promptitude in the application and unwearied exertion in the continuance of remedies. In severe English, as in Asiatic cholera, it is generally in the first stage that the battle is to be fought. A remedy which I have found very valuable is the decoction of logwood; it has so little unpleasantness of taste, and is so efficient, that it merits more frequent employment than, if I may judge from the remarks of my druggist, it obtains. I have used it in the proportion of two ounces of logwood to thirty-two ounces of water, boiled down to eight ounces, giving one ounce at a dose, with or without laudanum, as the case might require. I am, Gentlemen,

Your obedient servant,

Bath, 17, Westgate Buildings, JOWN BARR ET I Oct. 14, 1842

\section{TREATMENT OF UNUNITED FRACTURE.}

\section{TO TIIE LDITORS OF TIE PROVINCIAL MEDICAL} JOURNAL.

Gentleyen,-It not unfrequently happens, in cases of ununited fracture, even when treated in the most skilful manner, that the means employed will fail of bringing about a firm union, and a false joint is the consequence. The treatment of the following case, which proved successful, may, perhaps, be deemed worthy of attention, inasmuch as it combined an ancient practice modified by more recent improvements in surgery :-

J. 'T., aged forty-two, although given to intemperance, appeared not to have suffered any visible deterioration of health. On the 28th of March last he fell down, and fractured the tibia and fibula of the right leg. The medical gentleman who was called in at the time had him carefully conveyed home, and subsequently placed the limb on Liston's fracture apparatus. After having laid six weeks it was removed, and at the end of another month, being ten weeks from the accident, any attempt to use the limb, even by the aid of crutches, proved abortive, and was accompanied with an intense degree of pain.

At this juncture I was requested to sec the patient. Upon examination, the fractured ends of the bones were found ununited, and the limb, when rotated, elicited a distinct crepitating sound. The tibia was fractured obliquely, occupying a space nearly midway between the malleoli and knee-joint. The want of union appeared to have had no connection with the state of his health, which seemed not to have suffered materially since the accident, but, in all probability, arose either from a want of a perfect coaptation of the fractured extremities, caused possibly by the interposition of muscular fibre, or from the restless conduct of the patient, causing displacement of the bandages whilst the callus was forming, and thereby disappointing Nature in her work.

After considering the various means usually resorted to in the treatment of such cases, the following was resolved upon:-The limb being firmly grasped with both hands, the fractured ends were made quickly, but not roughly, to rub upon each other, the action being continued for the space of two or three minutes. This produced a very considerable degree of pain, which was ill borne by the patient. The limb was then simply placed upon a pillow, and nothing more done till the following morning, when the same process of attrition was repeated, and continued on the two succeeding days. The ends of the bones were then adjusted, and encircled, herring-bone fashion, with strips of soap plaster, and an eighteentailed bandage applied, being previously well starched. Strips of linen, two or three times doubled, and about two inches in breadth, soaked in the same ingredient, were placed longitudinally on its outside and anterior aspect. The limb then received an additional support above and below by a wooden splint, the whole being ultimately secured with tapes. At the end of two or three days it became so completely encased that no movement of the patient could in any degree disturb the adjusted ends of the bones. The apparatus was not removed until the end of six weeks, when, upon examination, it was found that union had taken 
place. The limb continued weak for a considerable time, and at the end of about ten weeks he was so far enabled to bear weight upon it as to allow of his crutches being laid aside, and walked with the aid of two sticks.

I remain, Gentlemen,

Your obedient servant,

W. C. Worthington,

Senior Surgeon to the Lowestoft Infirmary.

Lowestoft, October 24, 1842.

PROVINCIAL MEDICAL JOURNAL

SATURDAY, OCTOBER 29, 1842.

Attention has recently been directed to the condition of the insane poor in Wales, by the publication of a letter from the pen of Dr. Hitch, resident physician of the Gloucester Lunatic Asylum. The thanks of the community are amply due to Dr. Hitch for his exposure of a state of things which are a disgrace to a civilised country-a blot which we sincerely trust will, ere long, be erased by the well-timed appeal of Dr. Hitch. From the information collected by the gentleman whom we have just named, it would appear that, in the counties of Anglesea, Carnarvon, Denbigh, Flint, Merioneth, and Montgomery, containing a population of 396,254 souls, there are 664 (306 males, 358 females) insane persons chargeable to the different parishes within those counties as "lunatic paupers." This number, when compared with the population, gives about one pauper lunatic to every 596 of the whole population-about one male in 639, and one female in 560 . The number of the insane amongst the other classes could not be ascertained; but, from the inquiries made by Dr. Hitch, it seems probable that in numerical proportion they are at least equal to their poorer brethren.

The actual numbers of the insane poor in the different Welch counties may be taken to be as follows :-

In Anglesea, whose

population is . .50,890, there are 92 , or 1 in 553 In Carnarvon . . : 81,068 $146 \quad 555$

In Denbigh . . . 89,291 $105 \quad 850$

In Flint . . . 66,547 $62 \quad 1,073$

In Merioneth . . . 39,238 $\quad 101 \quad 388$

In Montgomery . . 69,220 $\quad 158 \quad 438$

664

These poor creatures are distributed and disposed of in the following manner :-

Males, Females. Total.

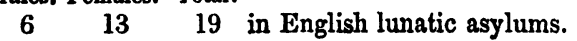

$17 \quad 15 \quad 32$ in Welch union workhouses.

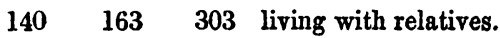

$\begin{array}{llll}143 & 167 & 300 & \text { living with strangers, or, more }\end{array}$

- - properly, "farmed out," at

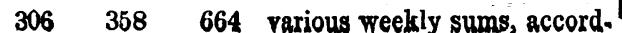

ing to the degree of utility they may afford to their respective masters.

The average cost of the patients differs according to their mode of distribution; and if we are to estimate the care bestowed on the lunatic by the sum of money expended for his keeping, many of these unfortunate creatures must suffer the utmost degree of privation.

The few who are in lunatic asylums cost their parishes, on an average, about 12s. per week; those in the workhouses about $2 \mathrm{~s}$. $3 \mathrm{~d}$. ; those with their relatives about 2s. 8d.; those with strangers about 3s. $2 \frac{1}{2} \mathrm{~d}$. The highest sum allowed to a relative is 5s. 6d.; to a stranger, 7s. per week. Several are stated to be provided for upon the handsome allowance of $9 \mathrm{~d}$. per week; whilst a few are said to sustain existence on the sum of threepence weekly.

From the foregoing facts we can easily deduce the condition of the insane poor population of the principality of Wales. More than six hundred persons, deprived of reason, are scattered throughout the country, often living on the charity of relations, or on a pittance inadequate to procure even the necessaries of life-without medical care or magisterial protection. The sufferings which they undergo are hypothetically described by Dr. Hitch; but past experience would lead us to think that his description falls short of reality.

"Many of the poor lunatics," says Dr. H., "would, unavoidably, be under severe restrictions. Some would be deemed unsafe to the public and themselves unless securely chained to the wall or the floor of their contracted apartments. Some would be thought well enough treated if confined to a chamber, and their food and their clothing supplied to them through some narrow opening; others would enjoy the outhouse and the society of the lower animals. Light clothing and spare diet would of course be prescribed in all cases as proper to bring down the high state of mania, and those who were melancholic and depressed would be happy, indeed, if left to their own wretchedness, and not roused up to shake off their lethargy and low spirits. Some are said to enjoy their freedom, and to roam uncontrolled about the country, and such must occur where so many are so totally unprotected."

To those who remember the condition of the insane poor many years ago, or have witnessed the wretched state to which they are reduced in some countries where no provision is made for their support or treatment, the above picture will not appear over-colored. But it may be asked, whence comes it that the condition of the insane poor in the principality of Wales is so deplorable? The answer is furnished by Dr. Hitch, who informs us that, with a single insignificant exception, there is not in the whole principality a lunatic asylum, either public or private, charitable or speculative. Some of the afflicted, indeed, are sent into the English asylums, but the transfer to what might be called a foreign country is anything but beneficial. The Welch poor are, universally, ignorant 